\title{
Radikal Prostatektomide Eksize Edilen Anterior Prostatik Yağ Dokuda Lenf Nodu Metastazını Predikte Eden Faktörler
}

\section{Predicting Factors for Lymph Node Metastasis in Anterior Prostatic Fat Tissue Excised During Radical Prostatectomy \\ Fatih AKKAŞ ${ }^{1} \mathbb{D}$, Yavuz Onur DANACIOĞLU 1 1D, Mustafa Gürkan YENICE ${ }^{1}$ (D), Kamil Gökhan ŞEKER ${ }^{2}$ (D) Selçuk ŞAHIN ${ }^{1}$ (D)}

\begin{abstract}
1 Sağlık Bilimleri Üniversitesi Bakırköy Dr.Sadi Konuk Eğitim ve Araştırma Hastanesi, Üroloji Kliniği, İstanbul,Türkiye 2 Muş Devlet Hastanesi, Üroloji Kliniği, Muş, Türkiye
\end{abstract}

Öz.

Amaç: Açık radikal prostatektomi ve robot yardımlı laparoskopik prostatektomide (RYLP) cerrahi alanın net görülmesi için eksize edilen anterior prostatik yağ dokusunda (APYD) lenf nodu insidansı ve lenf nodu metastazını etkileyen faktörlerin incelenmesi

Materyal ve Metod: Ocak 2018 ve Ocak 2020 arasında tek merkezde RYLP yapılan 219 hastadan eksize edilen APYD lenf nodu varlığı ve lenf nodu metastazı açısından histopatolojik olarak incelendi. Tanımlayıcı istatistikler ve çok değişkenli analiz kullanılarak APYD'da lenf nodu metastazını predikte eden faktörler araştırıldı.

Bulgular: APYD'da 21 olguda (9.5) lenf nodu saptandı. Bu olgular içerisinde 6 olguda (\%2.7) lenf nodu metastazı saptandı. 6 olgunun ikisi pelvik lenf nodu diseksiyonu (PLND) yapılmayan düşük ve orta riskli hastaydı. Diğer 4 olgunun ikisinde eş zamanlı olarak pelvik lend nodunda metastaz izlendi. APYD'da metastaz izlenen olgularda toplam tümör volümü, ISUP skoru ve patolojik T evresi tek değişkenli analizde metastaz olmaksızın lenf nodu olanlara göre daha yüksek saptandı. Çok değişkenli analizde ise bu faktörlerin APYD'da lenf nodu metastazını predikte etmediği görüldü.

Sonuç: APYD lenf nodu barındırdığı ve mevcut lenf nodlarında metastaz geliştiği kanıtlanan bir dokudur. APYD eksizyonu radikal prostatektomi sırasında cerrahi alanın net görülmesi için uygulanan rutin bir prosedür olduğu için eksize edilen bu dokuların da patolojik olarak incelenmesi evrelendirmenin daha doğru yapılmasına yardımcı olacaktır.

Anahtar Kelimeler: Prostat Kanseri, Radikal Prostatektomi, Anterior Prostatik Yağ Doku

Abstract

Background: Examination of the factors affecting lymph node incidence and lymph node metastasis in excised anterior prostatic fat tissue (APFT) in open radical prostatectomy and robot-assisted laparoscopic prostatectomy (RALP)

Materials and Methods: Between January 2018 and January 2020, 219 patients who underwent RALP in a single center were examined histopathologically for the presence of lymph node and lymph node metastasis. Factors predicting lymph node metastasis in APFT were investigated using descriptive statistics and multivariate analysis.

Results: Lymph node was detected in 21 cases (9.5\%) in APYD. Lymph node metastasis was detected in 6 cases (2.7\%). Two of the 6 cases were low and moderate risk patients without pelvic lymph node dissection (PLND). In two of the other 4 cases, metastasis was observed simultaneously in the pelvic lend node. In cases where metastasis was observed in APFT, total tumor volume, ISUP score, and pathological T stage were higher in univariate analysis than those with lymph node without metastasis. In multivariate analysis, these factors did not predict lymph node metastasis in APFT.

Conclusion: APFT is a tissue that has been proven to contain lymph nodes and metastases. Since APYD excision is a routine procedure applied to see the surgical field clearly during radical prostatectomy, pathological examination of these excised tissues will help make the staging more accurate.

Key words: Prostate Cancer, Radical Prostatectomy, Anterior Prostatic Fat Tissue
Sorumlu Yazar I

Corresponding Author

Dr. Yavuz Onur DANACIOĞLU

Sağlık Bilimleri Üniversitesi Bakırköy Dr.Sadi Konuk Eğitim ve Araştırma

Hastanesi, Üroloji Kliniği,

Tevfik Sağlam Caddesi No:11

Zuhuratbaba/Bakırköy, İstanbul

34147, Türkiye

e-mail: yavuzonurd@gmail.com

Tel: +90 5322935673

Fax: +90 2124146499

Geliş tarihi / Received: 27.04.2020

Kabul tarihi / Accepted: 07.07.2020

DOI: $10.35440 /$ hutfd.728011 


\section{Giriş}

Lokalize prostat kanserinin tedavisinde güncel tedavi metodları radyoterapi ve radikal prostatektomidir. Cerrahi yöntemler arasında fonksiyonel ve onkolojik sonuçlar açısından güncel literatürde fark saptanmamış olsa da robot yardımlı laparoskopik prostatektomi (RYLP) ABD, Avrupa ülkeleri ve dünyanın farklı ülkelerinde açık retropubik radikal prostatektomi yöntemini geçerek yaygınlaşmıştır(1).

Prostat, endopelvik fasya, puboprostatik bağlar, prostat ve mesane boynu arasındaki bağlantı yağ dokusu ile kaplıdır(Şekil 1).Robotik cerrahi esnasında anterior prostatik yağ dokusunun (APYD) diseksiyonu ve çıkarılması özellikle prostatik apeks olmak üzere dorsal venöz kompleks anterior yüzü ve puboprostatik ligament anatomisinin daha net görülmesini sağlar(2,3). Apikal anatominin daha iyi görülmesinin yanında apeks düzeyinde pozitif cerrahi sınır ihtimalini azaltmaktadır(4). Ayrıca APYD lenf nodlarının patolojik olarak incelenmesi muhtelif lenf nodu metastazlarını ortaya koyarak hastalık evresinin daha doğru belirlenmesini sağlar ve adjuvan tedavi modaliteleri uygulanabilir.

$\mathrm{Bu}$ çalışmada RYLP yapılan hastalarda eksize edilen APYD'da lenf nodu varlı̆ı, lenf nodu metastazı insidansı ve predikte eden faktörleri değerlendirdik.

\section{Materyal ve Metod}

Çalışma için etik kurul onayı alındıktan sonra (Bakırköy Dr. Sadi Konuk Eğitim ve Araştırma Hastanesi Klinik araştırmalar Etik Kurulu 03/12/2018 tarih ve 2018-22-15 sayılı karar), Ocak 2018-Ocak 2020 yılları arasında Sağık Bilimleri Üniversitesi Bakırköy Dr. Sadi Konuk Eğitim ve Araştırma Hastanesi üroloji kliniğinde RYLP yapılan 219 hastanın kayıtları retrospektif olarak gözden geçirildi. Tüm RYLP operasyonları transperitoneal yolla gerçekleştirildi. Transuretral cerrahi ve radyoterapi hikayesi olan hastalar çalışmadan çıkarıldı. Tüm hastalara prostat biopsisinden önce lokal evreleme amacıyla multiparametrik MRI (mpMRI) çekildi. Hastaların klinik evrelemesi tıbbi öykü, dijital rektal muayene, PSA, mpMRI ile belirlendi. D'Amico risk sınıflamasına göre yüksek riskli ve lokal ileri hastalığı olanlar belirlendi(5). Bu hastalara ek olarak kemik sintigrafisi ve abdominopelvik tomografi çekildi. Klinik evre ilgili ürolog tarafından 2017 tumor-node-metastaz (TNM) sistemi kullanılarak belirlendi. Klinik ve patolojik data enstitünün veritabanına prospektif olarak kaydedildi. Briganti nomogramı ile pelvik lenf nodu diseksiyonu yapılma kararı verildi(6).

RYLP prosedürü sırasında prostat, dorsal venöz kompleks, prostat apeksi, puboprostatik ligament, prostatovesikal bileşke ve mesane boynunu çevreleyen anterior prostatik yağ dokusu diseke edilerek radikal prostatektomi materyali ile birlikte patolojik inceleme için gönderildi (Şekil 1). Anterior prostatik yağ dokuları (APYD) lenfoid doku varlığı ve metastaz varlığı açısından değerlendirildi. Lenfoid doku varlığı saptandığında prostat kanser varlığı açısından prostat spesifik antijen (PSA) ve prostat spesifik asit fosfataz ile immün boyama yapıldı.

APYD'da lenf nodu olan olgular diğer olgularla, demografik özellikler, PSA, prostat hacmi, mpMRI PI-RADS skoru, klinik ve patolojik evre açısından karşılaştıııldı. APYD'da lenf nodu olanlar kendi içerisinde iki gruba ayrıldı. APYD lenf nodlarında karsinom metaztazı olan olgular metastaz olmaksızın sadece lenf nodu olan olgularla demografik özellikler, PSA, prostat hacmi, mpMRI PI-RADS skoru, klinik ve patolojik evre açısından karşılaştırıldı.

Kategorik veriler sayı ve yüzde olarak sunuldu. Sürekli değişkenlere ilişkin veriler genel olarak ortalama ve standart sapma olarak sunulmuştur. Normal olarak dağılan verilerin ortalamaları arasındaki fark bağımsız örneklemlerde $T$ testi kullanılarak karşılaştırıırken, normal olarak dağılmayan verilerin karşılaştırması için Mann-Whitney U testi kullanıldı. Kategorik değişkenlerin frekansları Pearson KiKare kullanılarak karşılaştıııldı. $P$ değeri $<0.05$ olduğunda istatistiksel olarak anlamlı kabul edildi. Çok değişkenli analiz kullanılarak APYD'da lenf nodu metastazını predikte eden faktörler ortaya konulmaya çalışıldı.

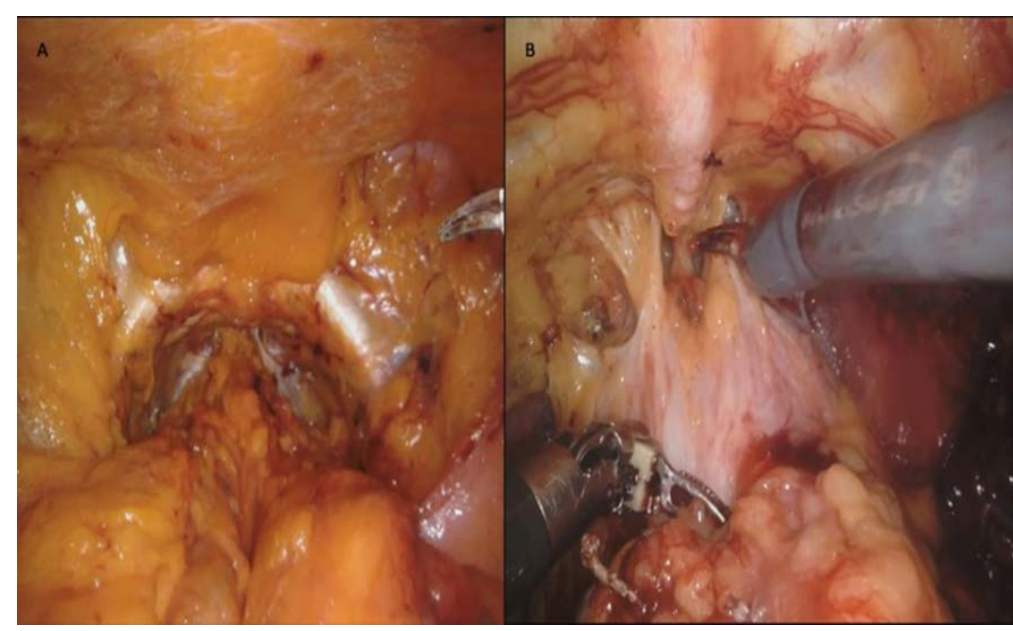

Şekil 1. A: Eksizyon öncesi anterior prostatik yağ dokusu görünümü; B: Anterior prostatik yağ dokusu eksizyonu sonrası görünüm

\section{Bulgular}

RYLP yapılan 219 hastadan operasyon esnasında eksize edilen APYD lenf nodu varlığı ve karsinom metastazı açısından incelendi. APYD'da lenf nodu 21 olguda (\%9.5), karsinom metastazı ise 6 olguda (\%2.7) saptanmıştır. 114 (\%52) hastaya genişletilmiş pelvik lenf nodu diseksiyonu uygulandı. APYD'da lenf nodu saptanan olgular diğer olgular ile demografik veriler, PSA, prostat volümü, transrektal biopsi ISUP skoru, mpMRI PI-RADS skoru, D'Amico risk sınıflaması, patolojik T evresi, prostatektomi materyalindeki toplam tümör volümü ve cerrahi sınır açısından karşılaştırıldı (Tablo 1). Her iki grup arasında istatistiksel olarak anlamlı farklılık saptanmadı. 
APYD'da lenf nodu olan olguların 6'sında lenf nodu metastazı saptanmış olup bu olguların 4'ü pelvik lenf nodu diseksiyonu uygulanmış yüksek riskli ve lokal ileri evre hastalığı olan olgulardı. Bu 4 hastanın 2'sinde eş zamanlı olarak pelvik lenf nodu metastazı saptandı.

Lenf nodu diseksiyonu uygulanmayan 2 olgu D'amico risk sınıflamasına göre düşük ve orta riskli hastalığı olan olgulardı. Bizim çalışmamızda tüm olgular göz önünde bulundurulduğunda \%1.8'inde APYD diseksiyonu ve patolojik incelenme sonucunda hastalık evresinin yükseldiği görüldü. APYD 'da pozitif olan lenf nodu sayısı 2'nin altında olduğu, hastalardaki tutulumunun mikroskopik düzeyde olduğu ve ekstranodal uzanım görülmediği için takip önerildi.

APYD'da prostat kanseri metastazı saptanan olgularda ortalama biopsi ISUP skoru, radikal prostatektomi tümör yüzdesi, patolojik T evresi tek değişkenli analizde istatistiksel olarak daha yüksek saptanmıştır (Tablo 2). Bununla birlikte yapılan çok değişkenli analizde her 3 parametrenin istatistiksel olarak anlamlı farklıık oluşturmadığı görülmüştür (Tablo 3).

Tablo 1. APYD'da lenf nodu olan olguların lenf nodu saptanmayan grup ile karşılaştırı Iması

\begin{tabular}{|c|c|c|c|c|}
\hline & $\begin{array}{lr}\begin{array}{l}\text { APYD } \\
\text { nodu } \\
(n=21)\end{array} & (+) \\
\end{array}$ & $\begin{array}{l}\text { APYD lenf } \\
\text { nodu }(-) \\
(n=198)\end{array}$ & $\begin{array}{l}\text { Toplam } \\
\text { hasta }(n=219)\end{array}$ & $p$ \\
\hline $\begin{array}{l}\text { Ortalama } \\
\text { yaş } \pm S S\end{array}$ & $62.80 \pm 3.40$ & $62.24 \pm 6.46$ & $62.29 \pm 6.23$ & 0.172 \\
\hline VKi $\left(\mathrm{kg} / \mathrm{m}^{2}\right)$ & $25.57 \pm 2.36$ & $25.07 \pm 1.89$ & $25.11 \pm 1.94$ & 0.258 \\
\hline PSA & $13.52 \pm 9.97$ & $13.57 \pm 16.83$ & $13.56 \pm 16.28$ & 0.990 \\
\hline PV & $47.38 \pm 15.21$ & $44.86 \pm 20.0$ & $46.24 \pm 20.83$ & 0.557 \\
\hline $\begin{array}{l}\text { Biopsi } \\
\text { ISUP grup }\end{array}$ & $1.85 \pm 0.96$ & $2.19 \pm 1.09$ & $2.15 \pm 1.08$ & 0.178 \\
\hline $\begin{array}{l}\text { PI-RADS } \\
\text { skoru }\end{array}$ & $3.80 \pm 1.36$ & $3.34 \pm 1.13$ & $3.38 \pm 1.16$ & 0.081 \\
\hline \multicolumn{5}{|l|}{$\begin{array}{l}\text { D' Amico } \\
\text { risk stratifi- } \\
\text { cation, } \\
\mathrm{n}(\%)\end{array}$} \\
\hline Düşük risk & $5(23.8)$ & 55 (27.8) & 60 & 0.162 \\
\hline Orta risk & $4(19)$ & $76(38.4)$ & 80 & \\
\hline Yüksekrisk & 7 (33.3) & 35 (17.7) & 42 & \\
\hline Lokal ileri & $5(23.8)$ & 32 (16.2) & 37 & \\
\hline
\end{tabular}

$$
\text { Patolojik }
$$$$
\mathrm{T} \text { evresi, }
$$$$
n(\%)
$$

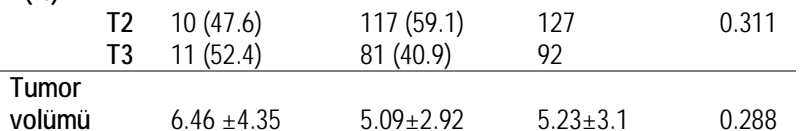

(ml)

Ortalama

\pm SS

Cerrahi

sınır, $n(\%)$

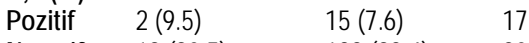

Negatif $19(90.5) \quad 183(92.4) \quad 202$

APYD, Anterior prostatic yağ dokusu; PV, Prostat volümü; SS, Standart sapma VKi, Vücut kitle indeksi

\section{Tartışma}

Güncel sistematik bir derlemede, radikal prostatektomi esnasında pelvik lenf nodu diseksiyonunun hastalığa özgü survi dahil onkolojik sonuçları etkilemediği gösterilmiştir(7). Bununla birlikte evreleme ve prognoz konusunda genişletilmiş pelvik lenf nodu diseksiyonunun verdiği bilgiler kullanılır(7). Avrupa Uroloji Derneği kılavuzunda Briganti nomogramı veya Roach formulü ile saptanan değerin \% $\%$ 'in üzerinde olmasının genişletilmiş lenf nodu diseksiyonu için endikasyon oluşturduğu belirtilmiştir(6,8,9).Biz hastalarımızda preoperatif değerlendirmede Briganti nomogramını kullanarak lenf nodu diseksiyonu kararını verdik.

APYD'da lenf nodu ve metastatik lenf nodu insidansı konusunda değişken veriler mevcuttur. Literatürde \%5.5 ile \%17 arasında değişen insidanslar belirtilmiştir(7-10,1314). Bizim çalışmamızda APYD'da lenf nodu sıklığı \%9.5 olarak saptanmıştır. 6 olguda (\%2.7) APYD'da metastatik lenf noduna rastlanmıştır. Finley ve arkadaşlarının 204 olguyu içeren çalışmasında 4 hastada (\%1.9), Jeong ve ekibinin 228 hastayı içeren çalışmasında ise 3 olguda (\%1.3) APYD'da metastatik lenf nodu saptanmıştır. Hosny ve Rai'nin 629 hastayı içeren çalışmasında ise sadece 3 olguda (\%0.3) APYD'da metastatik lenf nodu izlenmiştir. Literatürde bu konu ile ilgili yayınlanan çalışmalarda $\% 0.3$ ve $\% 2.5$ arasında değişen oranlar bildirilmiştir(10-16).

Tablo 2. APYD'da lenf nodu metastazı olan olguların lenf nodunda metastaz olmayan olgularla karşılaştııılması

\begin{tabular}{|c|c|c|c|}
\hline & $\begin{array}{l}\text { Lenf nodu } \\
\text { metastazı }(+) \\
(n=6)\end{array}$ & $\begin{array}{l}\text { Lenf nodu } \\
\text { metastazı } \\
(-)(n=15)\end{array}$ & $p$ \\
\hline Ortalama yaşıss & $63 \pm 3.68$ & $62.73 \pm 3.41$ & 0.876 \\
\hline VKi $\left(\mathrm{kg} / \mathrm{m}^{2}\right)$ & $26.28 \pm 2.23$ & $25.29 \pm 2.43$ & 0.400 \\
\hline PSA & $15.90 \pm 6.04$ & $12.57 \pm 11.21$ & 0.504 \\
\hline PV & $53.33 \pm 21.60$ & $61.66 \pm 25.68$ & 0.493 \\
\hline Biopsi ISUP grup & $2.66 \pm 0.51$ & $1.40 \pm 0.63$ & $<0.001$ \\
\hline PI-RADS skoru & $4.33 \pm 1.21$ & $3.60 \pm 1.40$ & 0.277 \\
\hline $\begin{array}{l}\text { D'Amico risk stratifica- } \\
\text { tion, } \mathrm{n}(\%)\end{array}$ & & & \\
\hline $\begin{array}{r}\text { Düşük risk } \\
\text { Orta risk } \\
\text { Yüksek risk } \\
\text { Lokal ileri }\end{array}$ & $\begin{array}{l}1(16.7) \\
1(16.7) \\
3(50.0) \\
1(16.7)\end{array}$ & $\begin{array}{l}5(33.3) \\
4(26.7) \\
2(13.3) \\
4(26.7)\end{array}$ & 0.362 \\
\hline $\begin{array}{r}\text { Patolojik T evresi, n(\%) } \\
\text { T2 } \\
\text { T3 }\end{array}$ & $\begin{array}{l}0(0.0) \\
6(100)\end{array}$ & $\begin{array}{l}10(66.7) \\
5(33.3)\end{array}$ & 0.006 \\
\hline $\begin{array}{l}\text { Tumor volümü(ml) Orta- } \\
\text { lama } \pm S S\end{array}$ & $10.16 \pm 3.76$ & $4.98 \pm 3.70$ & 0.01 \\
\hline $\begin{array}{r}\text { Cerrahi sınır, } \mathbf{n}(\%) \\
\\
\begin{array}{l}\text { Pozitif } \\
\text { Neqatif }\end{array}\end{array}$ & $\begin{array}{l}0(0.0) \\
6(100)\end{array}$ & $\begin{array}{l}2(13.3) \\
13(86.7)\end{array}$ & 0.347 \\
\hline
\end{tabular}

APYD, Anterior prostatic yağ dokusu; PV, Prostat volümü; SS, Standart sapma; VKI, Vücut kitle indeksi

Tablo 3. APYD lenf nodu metastazı için çok değişkenli analiz sonuçları

\begin{tabular}{llll}
\hline $\begin{array}{l}\text { Değişkenler } \\
\text { p }\end{array}$ & Odds oranı & \multicolumn{2}{c}{$\% 95$ Güven aralığı } \\
\hline ISUP skoru & 2.008 & $0.004-2.475$ & 0.157 \\
\hline Tümor volümü & 1.502 & $0.871-1.032$ & 0.254 \\
\hline Patolojik T3 evresi & & & 0.220 \\
\hline APYD, Anterior prostatic yağ dokusu & &
\end{tabular}


APYD'da lenf nodu ve metastatik lenf nodu varlığı ortaya konulmuş olmasına rağmen güncel kılavuzlarda genişletilmiş lenf nodu diseksiyonu şablonlarında kendisine yer edinememiştir. Finley ve arkadaşları APYD'nun pelvik yan duvardaki obturator lenf nodları ile direk bağlatısını göstermişlerdir(12). Bununla birlikte APYD diseksiyonu sonrası saptanan metastatik lenf nodları ile bazı olgularda hastalık evresinin yükseldiği gözlenmiştir. Kim ve arkadaşlarının yaptığı çalışma sonucunda hastaların $\% 0.63$ 'ünde patolojik evrenin yükseldiği gösterilmişsir(15). Jeong ve arkadaşlarının yaptığı çalışmada APYD'da metastaz saptanan 3 olgunun 2'sinde , Anning ve arkadaşlarının çalışmasında 4 olgunun hiçbirinde, Finley ve arkadaşlarının yaptığı çalışmada ise 4 olgunun sadece 1'inde eş zamanlı pelvik lenf nodu metastazı olduğu saptanmıştır(10-12).Bizim çalışmamızda tüm olgular göz önünde bulundurulduğunda \%1.8'inde APYD diseksiyonu ve patolojik incelenme sonucunda hastalık evresinin yükseldiği görüldü. Robotik radikal prostatektomi sırasında özellikle prostatik apeks olmak üzere dorsal venöz kompleks anterior yüzü ve puboprostatik ligament anatomisinin daha net görülmesini sağladığı için tüm olgularda uyguladığımız APYD diseksiyonu sırasında elde edilen materyalin patolojik incelemesinin yapılmasının önemi literatürde ve bizim çalışmamızda ortaya konulmuştur.

APYD'da lenf nodu oranını etkileyen faktörler bu konu ile ilgili literatürdeki çalışmalarda incelenmiştir. Atmaca ve arkadaşlarının yaptığı çalışmada APYD'da lenf nodu olan olguların prostat hacimlerinin lenf nodu saptanmayan gruba göre daha yüksek olduğu saptanmıştır(13). Jeong ve arkadaşlarının yaptığı çalışmada APYD'da lenf nodu olan olgularda preoperatif PSA düzeyi daha yüksek saptanmıştır(11). Bunun nedeninin preoperatif PSA düzeyi yüksek olan, pelvik lenf nodunda metastaz saptanan tüm olgularda aynı zamanda APYD'da da lenf nodu saptamaları olduğunu belirtmişlerdir.Bizim çalışmamızda her iki grup arasında preoperatif ve postoperatif bulgular açısından farklıIık saptanmamıştır.

APYD'da lenf noduna metastazı predikte eden faktörler incelendiğinde tek değişkenli analizde biopsi ISUP skoru, radikal prostatektomi tümör volümü ve patolojik evre açısından metastaz grubunda istatistiksel olarak anlamlı yüksek veriler elde edilmiştir. Aning ve arkadaşlarının yaptığı çaış̧mada da bizim çalışmamıza benzer şekilde tümör volümü, patolojik T evresi ve Gleason skoru yüksekliği açısından lenf nodu metastazı olan grupta ortalama ve insidanslar yüksek saptanmıştır(10). Çalışmamızda yapılan çok değişkenli analiz sonrasında her 3 parametrede iki grup arasında istatistiksel olarak anlamlı farkllık saptanmadı. Hansen ve arkadaşları APYD lenf nodunda karsinom metastazı belirleyicileri açısından yapılan çok değişkenli analizde yaş, PSA, ekstraprostatik uzanım, seminal vezikül invazyonu, biopsi Gleason skoru ve eksize edilen lenf nodu sayısı parametrelerinin istatistiksel olarak anlamlı farklıık oluşturmadığını saptamış olmakla birlikte patolojik lenf nodu evrelemesinin yeterli ve tam olduğunun düşünülmesi için APYD diseksiyonunun lenf nodu diseksiyonu şablonuna eklenmesi gerektiği görüşünü paylaşmışlardır(17).

Daha önce APYD'da lenf nodu ve metastaz oranını değerlendiren birçok çalışma literatürde kendine yer buldu. Bizim çalışmamız Hansen ve arkadaşlarının yaptığı çalışma ile birlikte APYD lenf nodu metastazını predikte eden faktörlerin araştırıldığı ikinci çalışmadır(17). Hansen ve arkadaşlarının çalışmasının lenf nodu metastazında araştırdığı seminal vezikül invazyonu, ekstraprostatik uzanım ve eksize edilen lenf nodu sayısı parametreleri bizim çalışmamızda incelenmemiştir. Bizim çalışmamız literatürdeki çalışmalardan farklı olarak gleason skoru yerine ISUP gruplamasını kullanmış ve PI-RADS skorunu APYD'da lenf nodu insidansı ve metastazı açısından ilk olarak inceleyen çalışma olmuştur. Çalışmanın retrospektif olması ve hasta volümünün literatürdeki çalışmalara kıyasla daha düşük olması kısıtlayıcı faktörlerdir.

\section{Sonuç}

Radikal prostatektomi esnasında APYD diseksiyonu ve eksizyonu prostatik apeks, endopelvik fasya ve dorsal venöz kompleks anatomisinin ortaya konulması açısından çok önemli rutin bir prosedür haline gelmiştir. Literatür verileri ve bizim çalışmamız düşük riskli prostat kanserinde bile APYD'da lenf nodu metastazını ortaya koymuş ve yüksek riskli prostat kanserlerinde bu oranın arttığını ortaya koymuştur. APYD'da lenf nodu ve metastatik lenf nodu varlığı ortaya konulmuş olmasına rağmen güncel kılavuzlarda genişletilmiş lenf nodu diseksiyonu şablonlarında kendisine yer edinemiştir. APYD eksizyonu radikal prostatektomi sIrasında cerrahi alanın net görülmesi için uygulanan rutin bir prosedür olduğu için eksize edilen bu dokuların da patolojik olarak incelenmesi evrelendirmenin daha doğru yapılmasına yardımcı olacaktır.

\section{Açıklamalar}

Etik Onam: Bakırköy Dr. Sadi Konuk Eğitim ve Araştırma Hastanesi Klinik araştırmalar Etik Kurulu 03/12/2018 tarih ve 2018-22-15 sayılı karar ile onay alınmıştır.

\section{Kaynaklar}

1. Gandaglia G, Sammon JD, Chang SL, Choueiri TK, Hu JC, Karakiewicz PI. Comparative Effectiveness of Robot-Assisted and Open Radical Prostatectomy in the Postdissemination Era. $\mathrm{J}$ Clin Oncol. 2014;32(14):1419-26.

2. Ahlering TE, Eichel L, Edwards RA, Lee DI, Skarecky DW. Robotic radical prostatectomy: A technique to reduce pT2 positive margins. Urology. 2004;64(6):1224-8.

3. Gil-Vernet JM. Prostate cancer: anatomical and surgical considerations. Br J Urol. 1996;78(2):161-8.

4. Salomon L, Anastasiadis AG, Levrel O, Katz R, Saint F, de la Taille A. Location of positive surgical margins after retropubic, perineal, and laparoscopic radical prostatectomy for organ-confined prostate cancer. Urology.2003;61(2):386-90. 
5. D'Amico AV, Whittington R, Malkowicz SB, Schultz D, Blank K, Broderick GA. Biochemical Outcome After Radical Prostatectomy, External Beam Radiation Therapy, or Interstitial Radiation Therapy for Clinically Localized Prostate Cancer. 280(11):6.

6. Briganti A, Larcher A, Abdollah F, Capitanio U, Gallina A, Suardi N. Updated nomogram predicting lymph node invasion in patients with prostate cancer undergoing extended pelvic lymph node dissection: The essential importance of percentage of positive cores. Eur Urol. 2012;61(3):480-7.

7. Fossati N, Willemse P-PM, Van den Broeck T, van den Bergh RCN, Yuan CY, Briers E. The Benefits and Harms of Different Extents of Lymph Node Dissection During Radical Prostatectomy for Prostate Cancer: A Systematic Review. Eur Urol. 2017;72(1):84-109.

8. Gandaglia G, Fossati N, Zaffuto E, Bandini M, Dell'Oglio P, Bravi CA. Development and Internal Validation of a Novel Model to Identify the Candidates for Extended Pelvic Lymph Node Dissection in Prostate Cancer. Eur Urol. 2017;72(4):632-40.

9. Roach M, Marquez C, Yuo HS, Narayan P, Coleman L, Nseyo UO. Predicting the risk of lymph node involvement using the pre-treatment prostate specific antigen and gleason score in men with clinically localized prostate cancer. Int J Radiat Oncol Biol Phys. 1994;28(1):33-7.

10. Aning JJ, Thurairaja R, Gillatt DA, Koupparis AJ, Rowe EW, Oxley J. Pathological analysis of lymph nodes in anterior prostatic fat excised at robot-assisted radical prostatectomy. J Clin Pathol.2014;67(9):78791.

11. Jeong J, Choi EY, Kang DI, Ercolani M, Lee DH, Kim W-J. Pathologic implications of prostatic anterior fat pad. Urol Oncol Semin Orig Investig.2013;31(1):63-7.

12. Finley DS, Deane L, Rodriguez E, Vallone J, Deshmukh S, Skarecky D. Anatomic Excision of Anterior Prostatic Fat at Radical Prostatectomy: Implications for Pathologic Upstaging. Urology. 2007;70(5):1000-3.

13. Atmaca AF, Canda AE, Keske M, Arslan ME, Kamaci D, Alkan E, Balbay MD.Does anterior prostatic fat tissue removed during robotic radical prostatectomy contain any lymph nodes? Cent Eur J Urol. 2015: 68:410-4

14. Yuh $B$, Wu $H$, Ruel $N$, Wilson $T$. Analysis of regional lymph nodes in periprostatic fat following robot-assisted radical prostatectomy: Lymph nodes in periprostatic fat. BJU Int.2012;109(4):603-7.

15. Kim IY, Modi PK, Sadimin E, Ha Y-S, Kim JH, Skarecky D. Detailed Analysis of Patients with Metastasis to the Prostatic Anterior Fat Pad Lymph Nodes: A Multi-Institutional Study. J Urol. 13;190(2):527-34.

16. Hosny M, Rai B, Aljaafari F, Agarwal S, McNicholas T, Boustead G. Can Anterior Prostatic Fat Harbor Prostate Cancer Metastasis? A Prospective Cohort Study. Curr Urol. 2016;10(4):182-5.

17. Hansen J, Budäus L, Spethmann J, Schlomm T, Salomon G, Rink M. Assessment of Rates of Lymph Nodes and Lymph Node Metastases in Periprostatic Fat Pads in a Consecutive Cohort Treated With Retropubic Radical Prostatectomy. Urology. 2012;80(4):877-82. 